\title{
Electrocatalytic Recovery of Elements from Complex Mixtures using Deep Eutectic Solvents
}

Andrew P. Abbott*a, Robert C. Harris ${ }^{\mathrm{a}}$, Fay Holyoak ${ }^{\mathrm{a}}$, Gero Frisch ${ }^{\mathrm{b}}$, Jennifer Hartley ${ }^{\mathrm{b}}$ and Gawen R. T. Jenkin ${ }^{\mathrm{c}}$

${ }^{\mathrm{a}}$ Department of Chemistry, University of Leicester, Leicester LE1 7RH, UK

binstitut für Anorganische Chemie, TU Bergakademie Freiberg, Leipziger Str. 29, 09599 Freiberg, Germany

${ }^{\mathrm{c}}$ Department of Geology, University of Leicester, Leicester LE1 7RH, UK

*Corresponding author: Fax: (+) 441162523789 E-mail: apa1@le.ac.uk

\section{ABSTRACT}

The dissolution and subsequent selective recovery of elements from complex mixtures naturally necessitates redox chemistry. The majority of processes involve hydrometallurgical dissolution followed by selective chemical precipitation or electrochemical winning. The atom and energy efficiencies of these processes are poor, leading to a large volume of aqueous waste which needs to be treated before disposal. In this study it is demonstrated that electrocatalysis is an atom effective method of carrying out digestion and subsequently recovering elements from solution. Here deep eutectic solvents are used to simplify the speciation of solutes and to allow redox potentials to be modified compared to standard aqueous values. The redox catalyst used is iodine, as it demonstrates high solubility, fast electron transfer and the ability to oxidise most elements, including precious metals such as gold. The efficacy of this electrocatalyic method is demonstrated using three samples; $\mathrm{Cu} / \mathrm{Zn}, \mathrm{Ga} / \mathrm{As}$ and $\mathrm{Au} / \mathrm{Ag} /$ sulfidic ore.

\section{KEY WORDS}

recycling, semiconductor, ionometallurgy; electrocatalysis; deep eutectic solvent; ionic liquid; 


\section{INTRODUCTION}

The processing and reprocessing of metals is probably one the largest sources of low-grade waste and one of the largest users of energy of any industrial sector. Elemental sustainability is a major issue with rare elements being used in increasingly complex materials. ${ }^{1}$ The separation of metals, particularly those present in small concentrations in alloys, ores and semiconductors, is a significant challenge. Metal processing is often based on high temperature processes ${ }^{2}$ or hydrometallurgical methods. ${ }^{3}$ These processes can be complex due to the diverse range of starting materials i.e. metals, oxides, sulphides, carbonates, phosphates, silicates, selenides, tellurides, and complex slags, sludges, slimes and alloys. In order to solubilise metal ores and waste, the solution based processes tend to use concentrated acids or bases. Species present in their elemental form must first be oxidised using a strong acid, such aqua regia, or other undesirable chemicals such as cyanides. ${ }^{4}$ If not properly contained, these substances can cause environmental damage, e.g. aqua regia is naturally corrosive and releases either $\mathrm{NO}$ or $\mathrm{NO}_{2}$ on reacting with metals. Subsequently, valuable compounds are recovered by precipitation, electrowinning, cementation, liquid-liquid extraction or ion exchange.

Semiconductor elements are an invaluable part of the electronics industry and have gained significant strategic importance through their use in applications such as solar panels, mobile phones, LEDs and liquid crystal displays. As more products including semiconductors are made and more natural supplies of their ores are used up, recovery and recycling of these elemental components is becoming more necessary for several reasons, the first of which is the increased demand for products, causing temporary shortages and price rises. Secondly, the environmental impact of mining and processing is high and some of the more toxic elements, such as arsenic and selenium, have strict disposal restrictions imposed on them and therefore recycling and reuse is an attractive alternative to the costs of disposal and re-mining. ${ }^{5}$

Different, less hazardous methods of metal solubilisation, involve the microbial leaching of electronic waste with the metabolites from either bacteria or fungi, e.g. Brandl et al. found that different types and amounts of metals could be leached depending on the particular organism used. ${ }^{6}$ Up to $90 \%$ of the $\mathrm{Al}, \mathrm{Cu}, \mathrm{Ni}$ or $\mathrm{Zn}$ present in the scrap could be leached into solution, whilst Sn and $\mathrm{Pb}$ were found to form precipitates instead.

A promising non-biological method is the use of ionic solvents to process metals. ${ }^{7}$ By switching away from hydrometallurgy, it is hoped that, under the absence of hydroxide, less hazardous reagents can be used to solubilise metal salts. The removal of water from the system will also mean that side electrode reactions involving water and its ionic constituents $\left(\mathrm{H}^{+}\right.$and $\left.\mathrm{OH}^{-}\right)$can be avoided and current efficiency can be improved. The solvent itself can be tailored to meet the needs of the systems being studied, through careful choice of both cationic and anionic components 
of the ionic liquid (IL). ${ }^{8}$ The choice of solvent has a pronounced effect on the speciation of any solutes and hence provides control over chemical properties such as solubility and redox potential.

Ionic liquids have been studied in depth for liquid-liquid extraction of metals., ${ }^{9,11}$ This does not circumvent the digestion stage involving mineral acids, but it does replace the use of organic solvents and complexing agents for metal ion extraction. Some studies have tailored the functional groups on the anion or cation of the ionic liquid to make a so-called task specific ionic liquid which is selective for a particular metal in the liquid. ${ }^{10,12,13,14}$ The complexity of these liquids does however mean that they have to be used in small volumes, but the selectivity can mean that significant process intensification can be achieved.

An alternative approach has been suggested using deep eutectic solvents (DESs), which are mixtures of quaternary ammonium salts (usually chlorides) and hydrogen bond donors, such as amides or polyols. ${ }^{15,16,17}$ The comparatively high chloride concentration of these ionic solvents (c.a. $5 \mathrm{~mol} \mathrm{dm}^{-3}$ ) means that oxide chemistry of metals can be lessened or even avoided completely. ${ }^{18} \mathrm{It}$ has been shown that many metal oxides show a greater solubility in these media, compared to ionic liquids with weaker anions. ${ }^{19}$ Electrochemical oxidation has been demonstrated for several metallic compounds, including superalloys, in electropolishing experiments. ${ }^{20}$ However, most technological waste comes in small pieces or powdered form and hence cannot be made into suitable anodes. Chemical oxidation is therefore the only viable way to solubilise these materials, but this is naturally chemical- and waste-intensive. The use of an electrocatalyst, i.e. a chemical oxidising agent that can be recovered in situ by an electrochemical reaction, could circumvent this issue and provide a sustainable solubilisation technique for polymetallic waste.

In the current study it is demonstrated that the iodine/iodide redox couple is a strong oxidising agent for solubilising metals in the DES Ethaline, a 1:2 molar ratio of choline chloride and ethylene glycol. Ethaline is both air and moisture stable, and can hence be used under atmospheric conditions. It has an electrochemical window of approximately $2 \mathrm{~V}$ on a Pt working electrode, ${ }^{21}$ which is sufficiently large that all redox processes related to the systems studied should be observed. In essence, electrocatalysis has great potential as a green method for solubilising and recovering metals as it has very high atom efficiency, by using, in effect, only electrons. Electrorefining uses the same principle but directly dissolves the metal from the anode. The advantage of electrocatalysis is that it no direct contact is required between the anode and the material to be oxidised. The method can hence be applied more widely to powdered and nonconducting materials, such as ores. 


\section{EXPERIMENTAL}

Ethaline, a 1 mol. eq. of choline chloride (Sigma Aldrich, $98+\%$ ) and 2 mol. eq. of 1,2ethanediol (ethylene glycol, Sigma Aldrich, 98 +\%), was prepared by the method described in previous publications. $^{16,22}$

Cyclic voltammetry (CV) was carried out using an Autolab/PGSTAT12 potentiostat, controlled by GPES software. A three-electrode system was employed, consisting of a $1 \mathrm{~mm}$ diam. Pt disc working electrode and a platinum foil counter electrode. The reference electrode consisted of a silver wire immersed in a $0.1 \mathrm{~mol} \mathrm{dm}^{-3}$ solution of $\mathrm{AgCl}$ in Ethaline and separated from the electrochemical cell by a Vycor glass frit. Prior to all measurements, the working electrode was polished with $0.5 \mu \mathrm{m} \gamma$-alumina paste, and then sonicated in distilled water to remove any alumina residue. Solutions were all $0.02 \mathrm{~mol} \mathrm{dm}^{-3}$, except for zinc and gallium. It was necessary to record the zinc voltammogram at a concentration of $0.3 \mathrm{~mol} \mathrm{dm}^{-3}$, due to there being a critical value below which nucleation will not occur onto a Pt electrode. Gallium chloride was used at $0.1 \mathrm{~mol} \mathrm{dm}^{-3}$.

To test the effectiveness of iodine as an oxidising agent, separate solutions of excess copper and zinc powders in Ethaline containing $0.1 \mathrm{~mol} \mathrm{dm}^{-3}$ iodine were made up and $150 \mu \mathrm{l}$ samples of the liquid extracted at regular intervals. Before analysis, the samples were filtered with a $0.45 \mu \mathrm{m}$ pore filter, and diluted with deionised water by a factor of 20. Inductively coupled plasma optical emission spectroscopy (ICP-OES) was carried out with a JY Ultima 2 ICP-OES.

For bulk digestion and recovery, two different systems were studied: copper/zinc powder, and crushed gallium arsenide wafer. The $\mathrm{Cu} / \mathrm{Zn}$ and GaAs powders were oxidised with $0.1 \mathrm{~mol} \mathrm{dm}^{-3}$ solutions of iodine in Ethaline, using an excess of the metal, at a temperature of $40-60^{\circ} \mathrm{C}$, over a period of 1-2 days, until the iodine had decolourised. An iridium oxide-coated titanium mesh was used as an anode. Before measurements it was rinsed with deionised water and acetone. A nickel cathode was selected for the $\mathrm{Cu} / \mathrm{Zn}$ system, and a copper cathode was selected for the $\mathrm{Ga} / \mathrm{As}$ system. The cathodes were degreased and cleaned via sonication in dichloromethane before deposition was carried out. Bulk deposition of copper from the $\mathrm{Cu} / \mathrm{Zn}$ system was carried out at 0.9 V, for 2 hours. Bulk deposition of arsenic from the Ga/As system was carried out at $2.3 \mathrm{~V}$, until all the arsenic had been recovered (5 days), at which point the cathode was replaced with a fresh copper cathode, and recovery of gallium carried out at $2.6 \mathrm{~V}$, for 2 days. The deposits were subsequently rinsed with deionised water and acetone to remove any remaining DES.

For the selective dissolution of electrum from sulfide based ore a sample of gold ore CGJ CON 002, was received from the adit of Cononish Gold Mine, Scotland owned by Scotgold Resources Ltd. The sample consists largely of the sulphide minerals pyrite $\left(\mathrm{FeS}_{2}\right)$, galena $(\mathrm{PbS})$, chalcopyrite $\left(\mathrm{CuFeS}_{2}\right)$ in a quartz matrix with minor amounts of electrum. The sample was mounted in a resin block and a cut face polished to show the textures in reflected light microscopy. Electrum is a 
naturally occurring alloy of gold with silver. The composition of the electrum grain that was leached was measured as approximately $50 \mathrm{wt} \% \mathrm{Au} / \mathrm{Au}+\mathrm{Ag}$ by EDX. Ethaline with $0.1 \mathrm{~mol} \mathrm{dm}^{-3}$ $\mathrm{I}_{2}$ was used to chemically remove the electrum grains component from the bulk sulphide gangue. The sample was placed into the electrolyte at $50{ }^{\circ} \mathrm{C}$ for 10 minutes with magnetic stirring. 2D optical images of the samples pre and post dissolution were captured on a Zeta Instruments Zeta 2000 optical profiler using the inbuilt Zeta3D software version 1.8.5.

Three placer gold concentrate samples from streams (Sample 1 = Crom Allt top, Sample 2 = Crom Allt mid reach, and Sample 3 = Coire Ghamnain) in the Tyndrum area, Scotland, within the exploration licence of Scotgold Resources Ltd. The gold in these samples is contained in electrum grains thought to have been derived from erosion of nearby primary hydrothermal ore veins similar to those in the Cononish gold mine (Hill NJ 2014). The grains are thus similar in composition and characteristics to the primary hydrothermal ore, although much larger than the majority of the electrum grains in the ore. Grains vary from 0.1 to $3 \mathrm{~mm}$ in diameter. Placer gold samples are inhomogeneous in nature and initial bulk compositions were estimated both by measuring compositions of a sample of grains from each sample by electron microprobe and XRF analysis of 0.17 to $0.5 \mathrm{~g}$ of sample. Bulk electrum compositions by XRF ranged between 65 and 76 wt\% $\mathrm{Au} / \mathrm{Au}+\mathrm{Ag}$, but individual grain compositions by electron microprobe varied from 99-44\% (averages 64-69\%, standard deviation 5-12\%). Thus subsample bulk compositions could vary somewhat from overall bulk values. Along with the electrum, there was 6-24\% aluminosilicate minerals and pyrite $\left(\mathrm{FeS}_{2}\right)$. In each experiment, approximately $90 \mathrm{mg}$ of concentrate was added to $3.0 \mathrm{~mL}$ of Ethaline with $0.1 \mathrm{~mol} \mathrm{dm}^{-3} \mathrm{I}_{2}$. These samples were then magnetically stirred at $50{ }^{\circ} \mathrm{C}$ for a total of 48 hours. The electrolytic recovery of the electrum was carried out by electrodepositing onto Ni sheet that had been mechanically roughened and then degreased using acetone. Iridium oxide-coated titanium mesh was used as the anode. Electroplating was carried out under a constant current of $4 \mathrm{~mA} \mathrm{~cm}^{-2}$ for 2 hours.

The surface morphologies of all deposits were characterised using scanning electron microscopy (SEM) and confirmation of the elemental analysis of the compositions was carried out by energy dispersive X-ray spectroscopy (EDX), using a Phillips XL30 ESEM instrument with an accelerating voltage between 15 and $20 \mathrm{keV}$, giving an average beam current of ca. $120 \mu \mathrm{A}$, and controlled by Spirit software. 


\section{RESULTS \& DISCUSSION}

\section{Iodine as an electrocatalytic leaching agent}

The approach used in this study was to employ deep eutectic solvents (DESs) as they can be used economically on a large scale and are formulated from biocompatible components. The liquid used in this study was Ethaline, which is a 1:2 mole ratio mixture of choline chloride and ethylene glycol. Compared to many other ionic solvents, it has the advantage of being moisture and air insensitive, making the solutions easy to handle under atmospheric conditions. This liquid has been used for a variety of metal processing methods and has been scaled up to $>1$ tonne for three processes. $^{23,24,25}$

A suitable electrocatalyst for metal processing should demonstrate fast electron transfer, be reversible, have high rates of mass transport, high solubility, and should be environmentally compatible in its reduced form. There are several possible oxidising agents which have been considered for this process, including halogens, peroxides and sulfoxides. Many of these require protons for the reaction to be reversible and it is only the halides which fulfil the above criteria in the absence of water. Chlorine was found to be insoluble in Ethaline but both bromine and iodine exhibit excellent solubility, c.a. $0.8 \mathrm{~mol} \mathrm{~kg}^{-1}$ for iodine at $20^{\circ} \mathrm{C} .{ }^{26}$ The bromine solution was found to decolourise over 25 hours. Hence, further experiments were confined to iodine, which showed no sign of reaction with the solvent, even after a week at $60{ }^{\circ} \mathrm{C}$. From a sustainability perspective iodine is available in large quantities and is environmentally benign once it has been reduced to iodide.

In water, iodine is poorly soluble $\left(1.14 \times 10^{-3} \mathrm{~mol} \mathrm{~kg}^{-1}\right)^{27}$ unless stabilised in a charge-transfer complex, such as triiodide. This complexation significantly lowers the redox potential and compromises the ability of iodine to oxidise metals. This is not the case in non-polar organic solvents but there the metal salts exhibit insufficient solubilities. ILs and DESs uniquely combine high redox potentials for iodine with good solubilities for both iodine and metal salts and even effect low redox potentials, i.e. easy oxidation, for many metals. ${ }^{28}$

Figure 1 shows the cyclic voltammetry of iodine which exhibits redox signals between 0.4 and $0.6 \mathrm{~V}$ vs AgCl/Ag. Two overlapping reduction and oxidation waves are observed. 


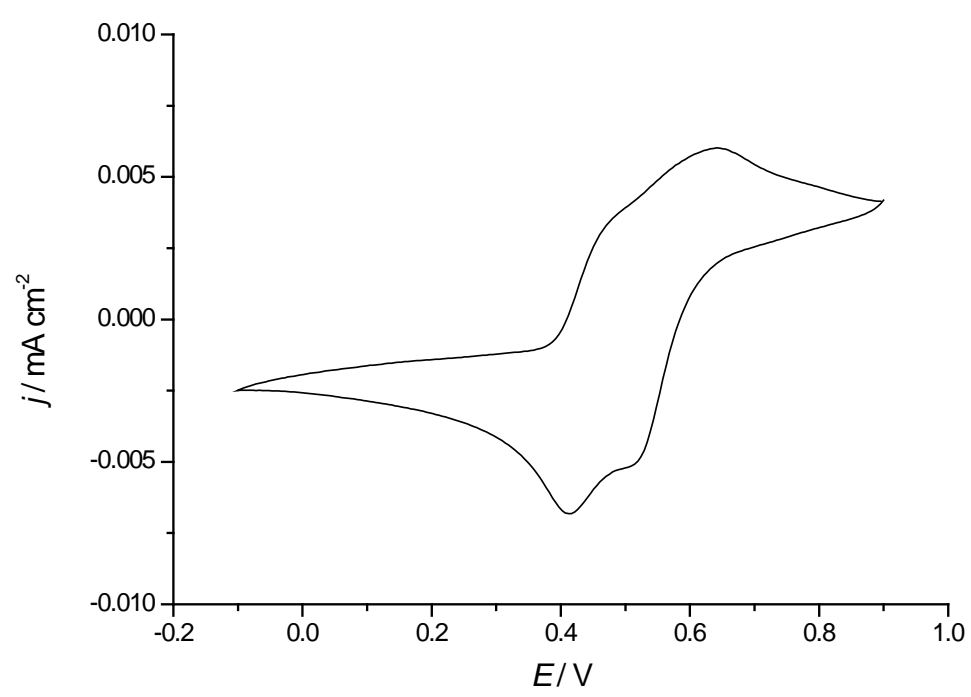

Figure 1: Cyclic voltammogram of iodine in Ethaline. Scans were recorded on $1 \mathrm{~mm} P t$ disc working electrode vs. Ag/AgCl in Ethaline reference, at a scan rate of $10 \mathrm{mV} \mathrm{s}^{-1}$.

It is suggested that a trihalide species forms in the diffusion layer of the electrode after initial reduction of $I_{2}$. The observed cyclic voltammetric response could hence be explained with two redox processes:

$$
\begin{gathered}
\mathrm{I}_{2}+2 \mathrm{e}^{-} \rightleftharpoons 2 \mathrm{I}^{-} \\
\mathrm{I}_{2}+\mathrm{I}^{-} \rightleftharpoons \mathrm{I}_{3}^{-} \\
\mathrm{I}_{3}^{-}+2 \mathrm{e}^{-} \rightleftharpoons 3 \mathrm{I}^{-}
\end{gathered}
$$

The reduction potential of iodine is quite high, compared to the oxidation potentials of copper, zinc, gallium and arsenic, which should allow oxidative leaching of these elements. In theory, the process should proceed as shown in the schematic in Figure 2, where both metals are simultaneously oxidised, followed by selective electrowinning of one metal at the cathode and recycling of iodine at the anode. In practice, it was necessary to separate the two electrodes from each other with some form of membrane to prevent constant cycling of iodine/iodide at the expense of metal deposition/current efficiency. 


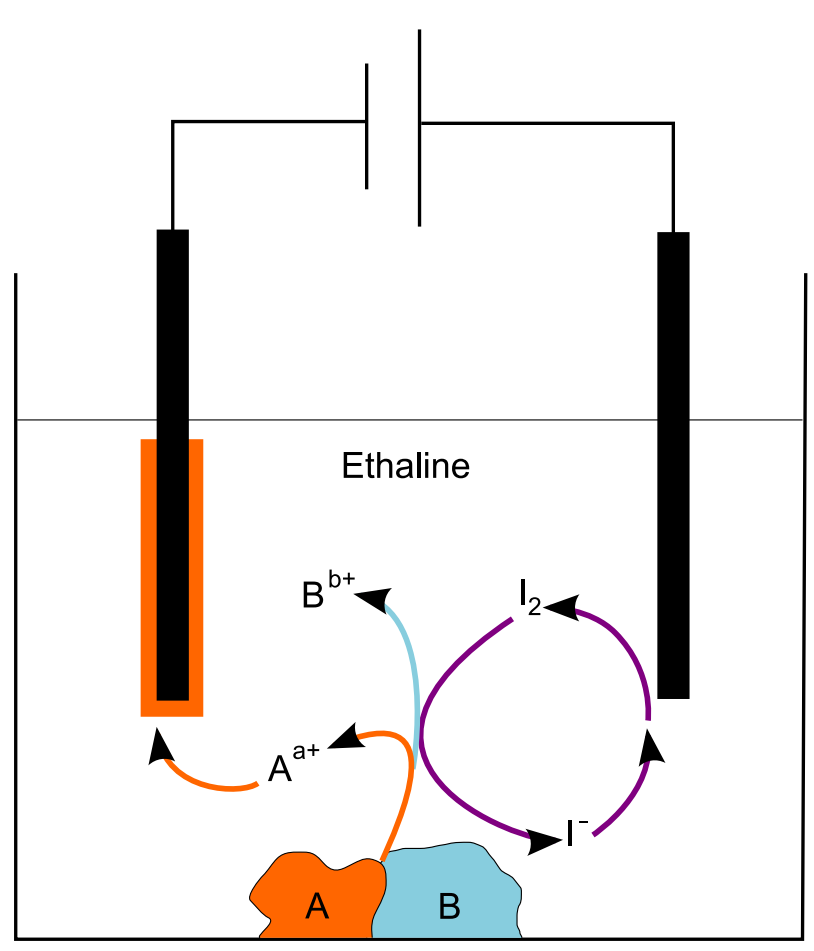

Figure 2: Schematic diagram of the separation and recovery of two elements, $A$ and $B$, using iodine as an electrocatalytic oxidation agent in Ethaline.

\section{$\mathrm{Cu} / \mathrm{Zn}$ model system}

To test the ability of iodine to act as an oxidising agent, experiments were performed to leach zinc and copper powder. These metals were chosen because their speciation and electrochemistry have been characterised previously, and there is also a significant difference between their reduction potentials of approximately $0.9 \mathrm{~V}$. Figure 3 shows the cyclic voltammograms of copper and zinc in Ethaline, with the voltammogram of iodine overlaid to visualise the general redox behaviour and differences in reduction as well as oxidation potentials. Both the $\mathrm{Cu}^{\mathrm{I} / 0}$ and $\mathrm{Zn}^{\mathrm{II} / 0}$ couples are significantly more cathodic than the iodine redox couples, suggesting that the leaching of copper and zinc should be possible. ${ }^{29,30,31} \mathrm{The} \mathrm{Cu}^{\mathrm{II/I}}$ and iodine redox couples are at very similar potentials, suggesting that $\mathrm{Cu}^{\mathrm{I}}$ will barely be oxidised to $\mathrm{Cu}^{\mathrm{II}}$ by iodine, at least as long as there is an excess of copper metal. This was observed in Figure 4, which shows two leaching experiments, one for zinc and one for copper powder, in Ethaline containing $0.1 \mathrm{~mol} \mathrm{dm}^{-3}$ of iodine. The metals are present in excess and the experiments were performed in quiescent solution. The solution of leached copper is mostly colourless, whilst a solution of $\mathrm{Cu}^{\mathrm{II}}$ in Ethaline is strongly yellow. ${ }^{7}$ 


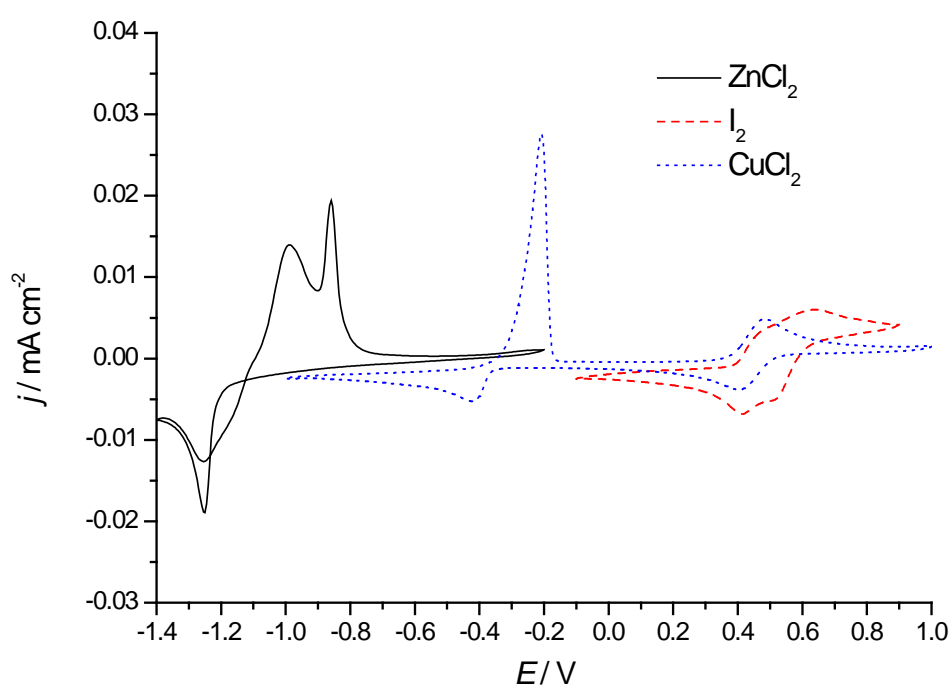

Figure 3: Cyclic voltammograms of $\mathrm{CuCl}_{2}, \mathrm{ZnCl}_{2}$ and iodine in Ethaline. Scans were recorded on $1 \mathrm{~mm}$ Pt disc working electrode vs. Ag/AgCl in Ethaline reference, at a scan rate of $10 \mathrm{mV} \mathrm{s}^{-1}$.

The concentrations of zinc and copper were monitored using ICP-OES analysis over the initial leaching period. The concentration of zinc in solution increases more rapidly than that of copper, which is consistent with the greater thermodynamic driving force for iodine to oxidise zinc. Figure 5 shows a plot of the solution concentrations of the metal ions versus the square root of time $\left(t^{1 / 2}\right)$. The linear relationship suggests that both reactions are diffusion controlled and therefore fast.

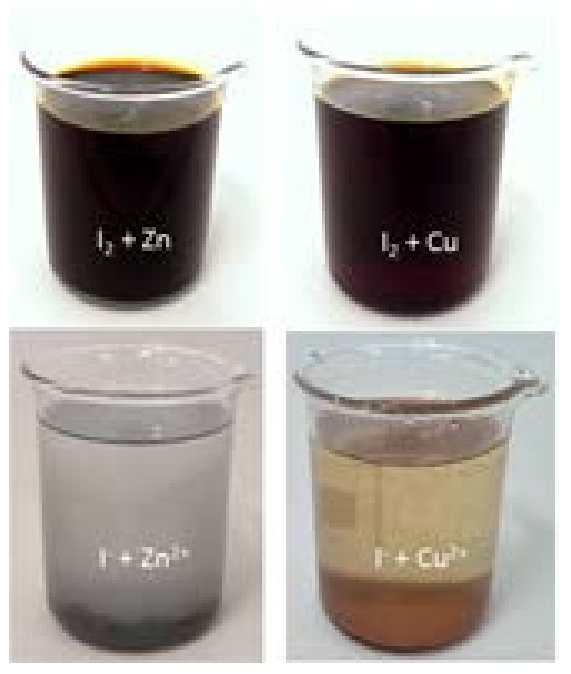

Figure 4: Samples of excess metal leached with $0.1 \mathrm{~mol} \mathrm{dm}^{-3}$ iodine in Ethaline, fresh (top) and after 2 days (bottom). 


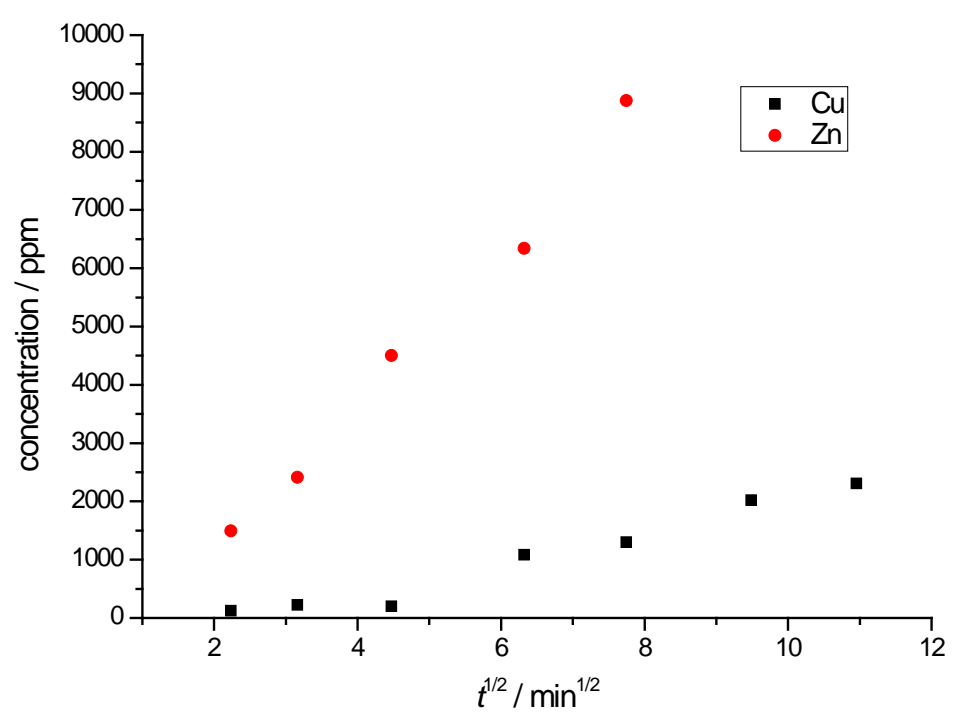

Figure 5: ICP-OES analysis of copper and zinc as they are leached by a solution of $0.1 \mathrm{~mol} \mathrm{dm}^{-3}$ iodine in Ethaline from their metal powders.

To evaluate the ability of this technique to separate metals in an electrocatalytic refining process, a 1:1 mixture of copper and zinc powder was leached with a stoichiometric amount of iodine at $40^{\circ} \mathrm{C}$ over 24 hours, which dissolved the majority of the metal powder. Subsequently, an electrode pair consisting of a 1 x $4 \mathrm{~cm}^{2}$ nickel cathode and an iridium oxide-coated titanium mesh anode was immersed in the solution, using a Soxhlet thimble as a separator between the anode and cathode compartments. A voltage of $0.9 \mathrm{~V}$ was applied and a copper deposit formed rapidly on the cathode. After 2 hours the current had dropped to less than $0.1 \mathrm{~mA}$, so it was assumed that all copper had been electrodeposited. During electrodeposition of the metals, the iodide can be recycled at the iridium oxide-coated titanium mesh anode, seen as 'waves' of iodine colour forming at the anode. The reformed iodine can then be used to oxidise any of the remaining metal powder therefore only requiring a catalytic amount of this as an oxidising agent. EDX analysis showed quantitative separation of the metals with no trace of copper being detectable in the zinc deposit.

\section{GaAs leaching and recovery}

As a slightly more complex example of the electrocatalytic methodology, the practical application of separating two elements from the semiconductor GaAs was tested. Some common semiconductor materials, such as gallium and indium, have no primary ore sources and are found in low concentrations e.g. in the sulphidic ores of $\mathrm{Zn}, \mathrm{Cu}$ and $\mathrm{Pb}$ (for $\mathrm{In}$ ) or in $\mathrm{Al}, \mathrm{Zn}$ and $\mathrm{Ge}$ (for $\mathrm{Ga}$ ), and are recovered as by-products of refining processes. ${ }^{32,33}$ By recycling products containing these elements, a more steady supply can be obtained leading to a sustainable economy of these strategically important compounds. 
Current recycling processes for waste semiconductor materials tend to include a series of leaching steps involving strong acids, bases, ligands and other toxic and reactive substances, such as hydrazine. $^{34}$ Alternative methods involve pyrometallurgical processes, however stringent plant control is required to avoid acute poisoning risks. ${ }^{35}$

The electrochemical behaviour of the p-block elements has not been extensively studied in DESs. Endres et al. have investigated elemental semiconductors, such as Si and Ge, together with their mixtures $\left(\mathrm{Si}_{\mathrm{x}} \mathrm{Ge}_{1-\mathrm{x}}\right)$ and some compound semiconductors, such as GaAs, AlSb, InSb, ZnTe, CdTe and CuInSe $e_{2}$, in other ionic liquids. It has been shown that a wide variety of compositions can be deposited by varying the concentration of salts in solution. Heat treating the electrodeposited samples yields semiconductors with useful bandgaps. ${ }^{36,37}$

The applied system chosen was that of the separation of gallium and arsenic from GaAs wafers, a very common semiconductor material. Gallium is a strategic metal with no primary ore sources, and arsenic is highly toxic and ideally should be recovered rather than released into the ecosystem via landfill.

Both $\mathrm{As}^{\mathrm{III} / 0}$ and $\mathrm{Ga}^{\mathrm{III} / 0}$ display quasi-reversible electrochemical behaviour in Ethaline (Figure 6) and can easily be bulk-deposited onto a platinum or copper electrode. Most arsenic and gallium salts exhibit good solubility in Ethaline, which is not surprising given that solubility in water is enhanced in the presence of chloride. The oxidation potentials of both elements in Ethaline are much more negative than that of iodine, suggesting that electrocatalytic oxidation is thermodynamically feasible.

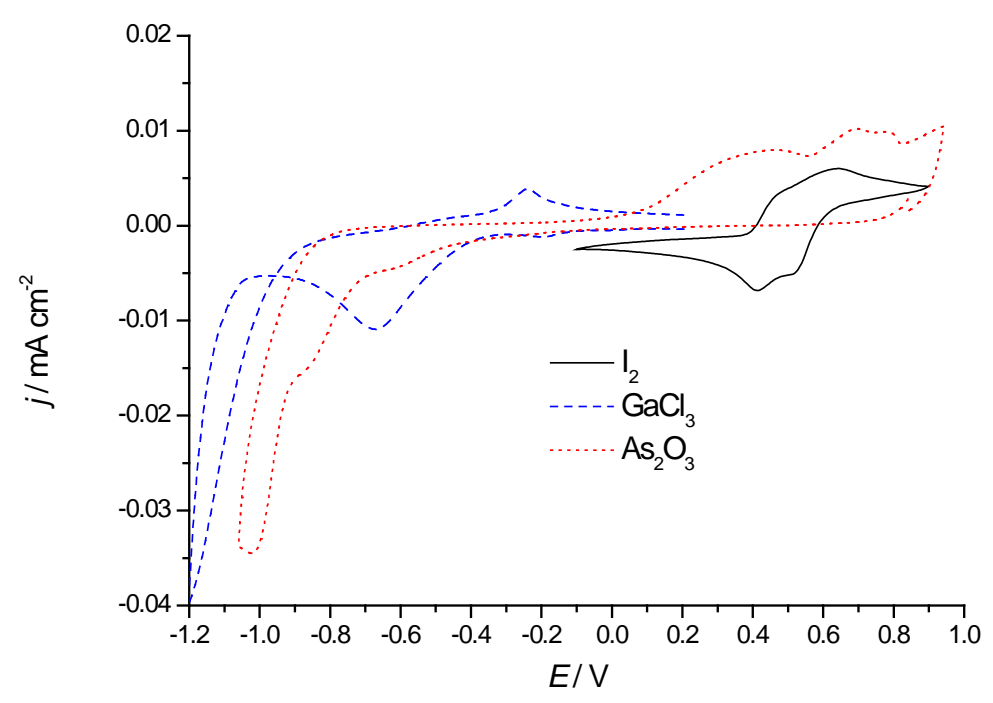

Figure 6: Cyclic voltammograms of $\mathrm{GaCl}_{3}, \mathrm{As}_{2} \mathrm{O}_{3}$ and iodine in Ethaline. Scans were recorded on a $1 \mathrm{~mm}$ Pt disc working electrode vs. Ag/AgCl in Ethaline reference, at a scan rate of $10 \mathrm{mV} \mathrm{s}^{-1}$.

From the $\mathrm{CV}$ of $\mathrm{GaCl}_{3}$, two reduction peaks are visible, suggesting that the reduction of $\mathrm{Ga}^{\mathrm{III}}$ to $\mathrm{Ga}^{0}$ takes place in two steps: a reduction from $\mathrm{Ga}^{\mathrm{III}}$ to $\mathrm{Ga}^{\mathrm{I}}$, followed by $\mathrm{Ga}^{\mathrm{I}}$ to $\mathrm{Ga}^{0}$. This 
two-step reduction was also observed in chlorogallate mixtures. ${ }^{38}$ A single oxidation peak is visible, suggesting that oxidation proceeds either straight to the $\mathrm{Ga}^{\mathrm{III}}$ species, or that the $\mathrm{Ga}^{\mathrm{I}}$ species dissociates rapidly during the timescale of the experiment. The CV of an $\mathrm{As}^{\mathrm{III}}$-solution shows a single reduction peak, corresponding to the deposition of As. Multiple oxidations peaks were observed, which may be due to different species or oxidation states forming in solution.

Importantly, the deposition potentials of gallium and arsenic are more than $300 \mathrm{mV}$ apart. This suggests that electrolytic separation should be viable. A large separation of the gallium and arsenic deposition peaks has also been observed during the deposition of GaAs from chloroaluminate and -gallate melts, which may be the reason why in these experiments the GaAs deposits were strongly contaminated with Ga and As. ${ }^{39,40}$

For the bulk leaching and recovery of gallium and arsenic from GaAs wafer-material, the same leaching process as described previously was applied. A copper cathode was substituted for nickel, as neither arsenic nor gallium deposited readily onto nickel. This also gave the added advantage of a clearer visual contrast of both of the elements prior to carrying out EDX analysis. As previously observed for the $\mathrm{Cu} / \mathrm{Zn}$ system, the iodine solution decolourised, indicating a leaching process.

The bulk deposition to remove all of the arsenic was carried out at $2.30 \mathrm{~V}$ for $c a$. 5 days at 40 ${ }^{\circ} \mathrm{C}$ before the cathode was replaced and the potential was increased for the recovery of the gallium at $2.60 \mathrm{~V}$. The arsenic recovery produced a dark grey metallic deposit, whilst the deposit obtained from the gallium recovery was shiny silver coloured. The morphologies of both of these deposits are shown in the SEM image in Figure 7.

To confirm the selectivity and purity of this recovery method, both cathodes were examined with EDX, which indicated that both elements had been electrowon with a purity $>99 \%$.
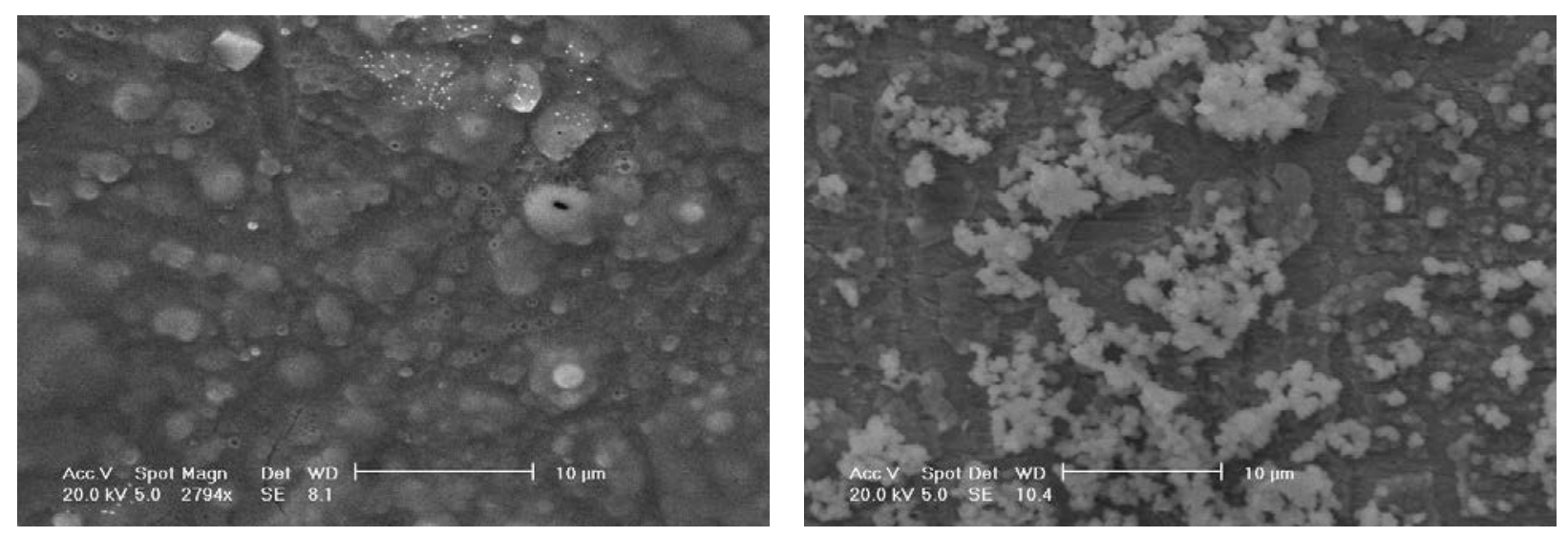

Figure 7: Scanning electron micrograph of arsenic (left) and gallium (right) electrowon from the GaAs wafer in $0.1 \mathrm{~mol} \mathrm{dm}^{-3}$ iodine in Ethaline at $2.30 \mathrm{~V}$ and $2.60 \mathrm{~V}$, respectively. 


\section{Extraction and recovery of gold and silver from ores}

The extraction of precious metals from their ores or scrap electronic waste can be a laborious process. The increased use of these metals in catalytic, aesthetic and electronic applications makes the need for efficient extraction techniques all the more important. Metals such as gold are often extracted using environmentally hazardous processes such as cyanidation;

$$
4 \mathrm{Au}+8 \mathrm{NaCN}+\mathrm{O}_{2}+2 \mathrm{H}_{2} \mathrm{O} \rightarrow 4 \mathrm{Na}\left[\mathrm{Au}(\mathrm{CN})_{2}\right]+4 \mathrm{NaOH}
$$

Attempts have been made previously to extract gold from ores using iodine/iodide from aqueous solution although the gold was not recovered. ${ }^{41}$ Concurrent work used ion exchange to recover gold from solution but it was found to be sensitive to the iodide concentration. ${ }^{42}$

In the current study we demonstrate the ability of the $0.1 \mathrm{~mol} \mathrm{dm}^{-3} \mathrm{I}_{2}$ containing Ethaline to selectively remove $\mathrm{Au} / \mathrm{Ag}$ ore grains from sulfide based gangue and we show that both metals can be recovered electrolytically from the electrolyte after dissolution. Selective dissolution from the gangue was studied using an electrocatalytic process similar to the one described above. Oxidation of thin gold films with iodine has previously been used as a method of recovering microfossil samples after gold coating for SEM analysis, however no recovery was attempted of the gold. Here, the process is applied to the leaching of concentrates of natural placer gold samples, with a view to recovering the gold afterwards. These samples are actually electrum, a natural alloy of gold and silver; sample gold concentration varies from $49-71 \%$, silver $22-27 \%$, and the remainder is $6-24 \%$ aluminosilicate minerals and pyrite $\left(\mathrm{FeS}_{2}\right)$.

Figure 8 shows the CVs for both gold chloride and iodine in Ethaline. Both exhibit redox couples at very similar potentials, which would imply that the reaction should not proceed. Closer inspection reveals that iodine undergoes two redox processes: the reduction of $\mathrm{I}_{2}$ and $\mathrm{I}_{3}{ }^{-}$, respectively, as described above. The more anodic couple has a slightly higher redox potential than $\mathrm{Au}^{\mathrm{I} / 0}$, suggesting that a sufficiently high concentration of iodine should enable the oxidation of gold. This has previously been applied to the dissolution of thin gold coatings on microfossil SEM samples. 


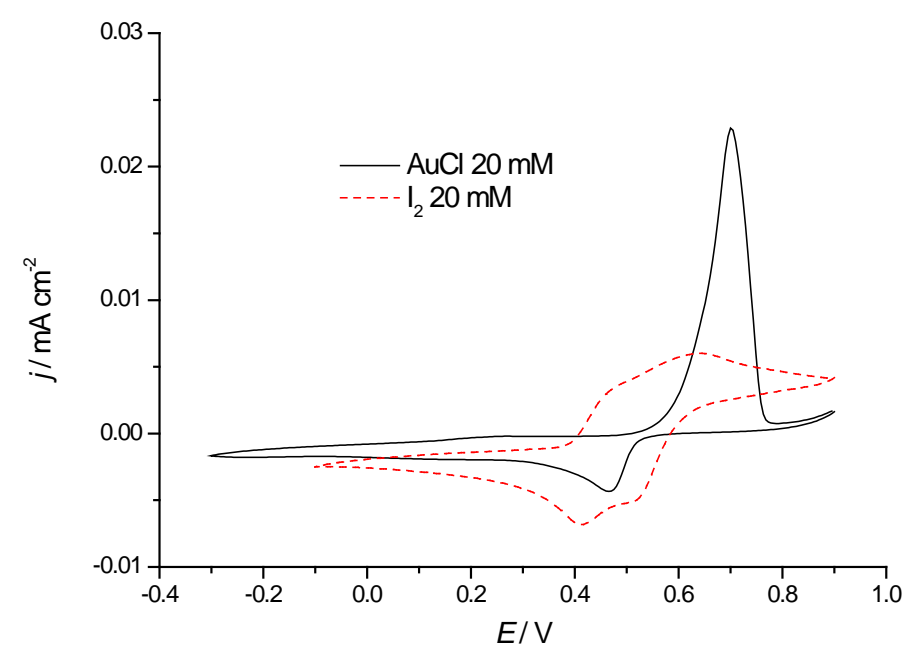

Figure 8: Cyclic voltammograms of $\mathrm{AuCl}$ and iodine in Ethaline. Scans were recorded on $1 \mathrm{~mm}$ $\mathrm{Pt}$ disc working electrode vs. Ag/AgCl in Ethaline reference, at a scan rate of $10 \mathrm{mV} \mathrm{s}^{-1}$.

In ores $\mathrm{Au}$ is present at much smaller concentrations (typically $<<100 \mathrm{ppm}$ ) and in hydrothermal ores it is often found with a variety of sulfides such as pyrite $\left(\mathrm{FeS}_{2}\right)$ and galena $(\mathrm{PbS})$. To show the selectivity of the electrocatalytic process for gold, a sample of hydrothermal ore from the source region of the placer material was embedded in resin and mechanically polished to a smooth finish, then treated using iodine in Ethaline. The gold in this sample is also found in the form of electrum. The weight ratio of gold: silver in this sample was approximately 50:50. As can be seen in Figure 9, the electrum grain was completely etched away after 10 minutes in the $\mathrm{I}_{2}$-containing Ethaline. Although etching of the galena was observed, there is no apparent etching of the pyrite phase, which is the major gangue (waste) component. This graphically demonstrates the selectivity of the process towards gold.
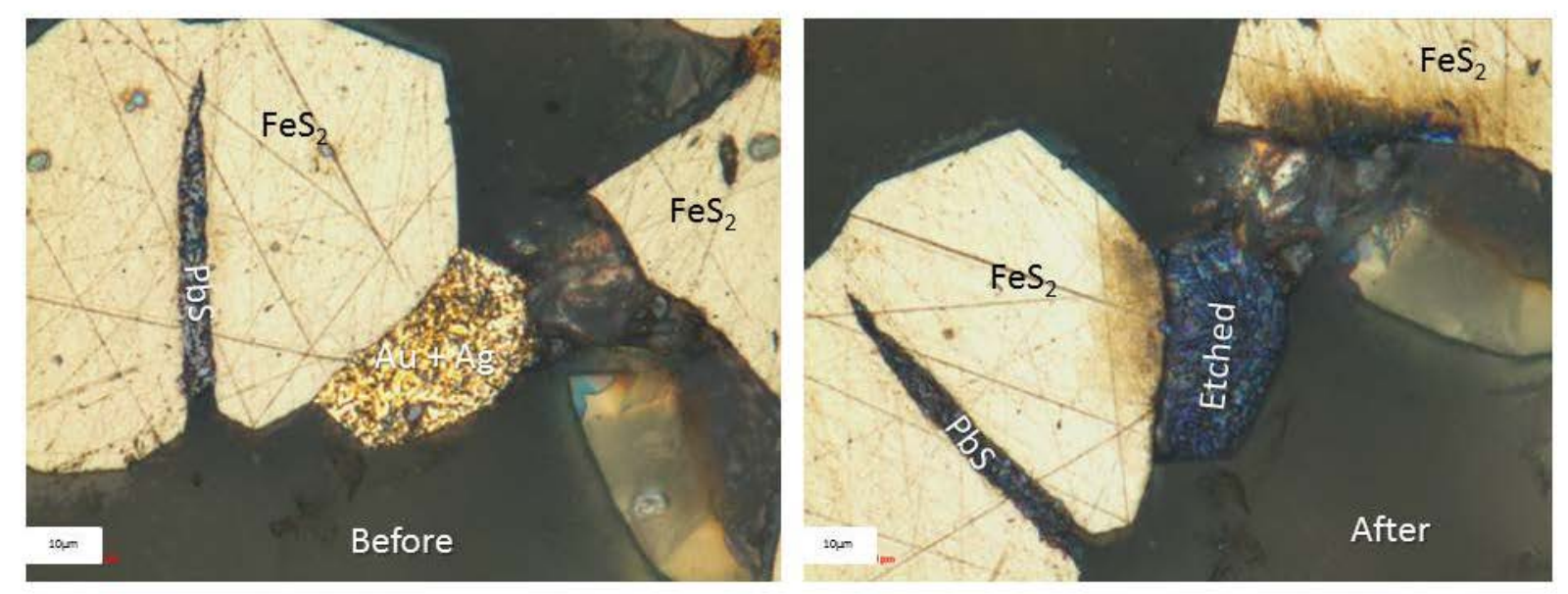

Figure 9: Reflected light optical microscopy image of polished gold-containing ore sample before (left) and after (right) leaching with $0.1 \mathrm{~mol} \mathrm{dm}^{-3} \mathrm{I}_{2}$ in Ethaline. Au+Ag is the alloy electrum. 
Recovery of the Au from the ore post dissolution is clearly a requirement of the mining industry. To demonstrate that it is possible to electrolytically recover the gold and silver from the electrolytes three different placer gold concentrates (approx. $90 \mathrm{mg}$ each) were individually leached in $3.0 \mathrm{~mL}$ of Ethaline with $0.1 \mathrm{~mol} \mathrm{dm}^{-3} \mathrm{I}_{2}$ over 48 hours at $50{ }^{\circ} \mathrm{C}$. Electrodeposition was carried out onto Ni sheet for a total of 20 hours for samples 1 and 2, and a total of 2 hours for sample 3, all at a current density of $4 \mathrm{~mA} \mathrm{~cm}{ }^{-2}$. The longer electrodeposition experiments resulted in very thick powdery brown/black deposits. The shorter electrodeposition time resulted in the same morphology deposit which was considerably thinner. Elemental composition of these deposits was carried out using EDX and the results found that the deposit contained no metallic compounds other than Au and Ag, demonstrating that this process is capable of recovering these elements from complex mineral mixtures. Furthermore, EDX data of each of the deposits shows that the weight \% of Au in each of the three deposits is $70 \%, 82 \%$ and $83 \%$, whereas in their pre-digested state the electrum contained 67\%, 64\% and 69\%, respectively, suggesting that the $\mathrm{Au}$ is being preferentially concentrated in all three precipitates. Given the difference in the redox potentials between gold and silver (c.a. $0.6 \mathrm{~V})^{28}$ it should be possible to get quantitative separation of the metals, however this is likely to be a slower recovery process.

\section{Conclusions}

Chloride-based DES, such as Ethaline, have a unique combination of properties that include the high solubility of a range of neutral and charged species. In this study, it has been discovered that iodine has a significantly greater solubility in a DES environment than in water, and displays reversible redox behaviour whilst maintaining a high redox potential. These properties allow the use of iodine as a benign, yet strong, electrocatalytic oxidising agent for a range of different metal mixtures.

Two mixed metal systems have been investigated in Ethaline: a model $\mathrm{Cu} / \mathrm{Zn}$ system and GaAs wafer-material. The oxidation potentials of the four elements were significantly lower than the reduction potential of iodine, allowing electrocatalytic oxidation to proceed. Their deposition potentials were sufficiently separated from each other that the individual elements could be recovered via electrowinning to a purity of $>99 \%$.

The extraction of gold from a complex concentrate using an electrocatalytic method has also been demonstrated showing that this methodology could be appropriate to primary metal recovery. Despite the redox potential for gold and iodine being close together the $\mathrm{I}_{2} \mathrm{Cl}^{-}$formed in solution is a strong enough oxidising agent to oxidise even the most noble of metals.

The atom efficiency of the process is theoretically very high and selectivity can be obtained through speciation differences in the chloride-rich environment, as opposed to water. We can 
dissolve electrum, a natural gold-silver alloy which is the main ore of gold, both from gold concentrates and natural ore samples. The gold and silver can be recovered electrolytically, currently together (with some potential biasing towards gold recovery), but with the potential of further developments that ultimately they can be recovered separately.

\section{ACKNOWLEDGEMENTS}

The authors thank the EPSRC and 5NPlus for a studentship for JH. Gold samples were collected and kindly donated by Dr Robert Chapman (University of Leeds). 


\section{REFERENCES}

1 J. R. Dodson, A. J. Hunt, H. L. Parker, Y. Yang, J. H. Clark, Chem. Eng. Proc. 2012, 51, 69.

2 F. Habashi, Principles of Extractive Metallurgy: Pyrometallurgy, Vol 3. Gordon and Breach, New York, 1986.

3 C. K. Gupta and T. K. Mukherjee, Hydrometallurgy in extraction processes, CRC Press, Boca Raton, Fla., 1990.

4 P. G. Spry, S. Chryssoulis, C. G. Ryan, JOM, 2004, 56, 60.

5 J. Cui and L. Zhang, J Hazard Mater, 2008, 158, 228.

6 H. Brandl, R. Bosshard and M. Wegmann, Hydrometallurgy, 2001, 59, 319.

7 A. P. Abbott, G. Frisch, J. Hartley and K. S. Ryder, Green Chemistry, 2011, 13, 471.

8 A. P. Abbott, G. Frisch and K. S. Ryder, Annual Reports on the Progress of Chemistry, Section A: Inorganic Chemistry, 2008, 104, 21.

9 A. Rout and K. Binnemans, Dalton Trans., 2014, 43, 3186.

10 P. Nockemann, B, Thijs, S. Pittois, J, Thoen, C. Glorieux, K. van Hecke, L. van Meervelt, B. Kirchner, K. Binnemans, J. Phys. Chem. B, 2006, 110, 20978.

11 S. Wellens, R. Goovaerts, C. Möller, J. Luyten, B. Thijs, K. Binnemans, Green Chem., 2013, 15, 3160.

12 J. H. Davis Jr., Chem. Lett., 2004, 33, 1072.

13 A. E. Visser, R. P. Swatloski, W. M. Reichert, R. Mayton, S. Sheff, A. Wierzbicki, J. H. Davis Jr. and R. D. Rogers, Environ. Sci. Technol., 2005, 36, 2523.

${ }^{14}$ A. E. Visser, R. P. Swatloski, W. M. Reichert, J. H. Davis, R. D. Rogers, R. Mayton, S. Sheff and A. Wierzbicki, Chem. Commun., 2001, 135.

15 A. P. Abbott, G. Capper, D. L. Davies, H. L. Munro, R. K. Rasheed and V. Tambyrajah, Chem. Commun., 2001, 2010.

16 A. P. Abbott, D. Boothby, G. Capper, D. L. Davies and R. K. Rasheed, J. Am. Chem. Soc., 2004, 126, 9142.

17 A. P. Abbott, R. C. Harris, K S. Ryder, C. D’Agostino, L. F. Gladden, M. D. Mantle, Green Chem., 2011, 13, 82.

18 J. M. Hartley, C.-M. Ip, G. C. H. Forrest, K. Singh, S. J. Gurman, K. S. Ryder, A. P. Abbott, G. Frisch, Inorg. Chem., 2014, 53, 6280.

19 A. P. Abbott, G. Capper, D. L. Davies, K. J. McKenzie, S. U. Obi, J. Chem. \& Eng. Data, 2006, 51, 1280. 
${ }^{20}$ A. P. Abbott, G. Frisch, “Ionometallurgy: Processing of Metals using Ionic Liquids” A. Hunt Ed. RSC Green Chemistry Element Recovery and Sustainability, Royal Society of Chemistry, Cambridge, 2013

${ }^{21}$ S. Ghosh, S. Roy, Surf. Coat. Tech., 2014, 238, 165.

${ }^{22}$ A. P Abbott, G. Capper, D. L. Davies, R. K. Rasheed, V. Tambyrajaha, Chem. Commun., 2003, 70.

23 A. P. Abbott, J. Collins, I. Dalrymple, R. C. Harris, R. Mistry, F. L. Qiu, J. Scheirer and W. R. Wise, Aust. J. Chem., 2009, 62, 341.

${ }^{24}$ E. L. Smith, C. Fullarton, R. Harris, S. Saleem, A. P. Abbott, K. S. Ryder, Trans. Inst. Metal. Finish., 2010, 88, 285.

${ }^{25}$ E. L. Smith, A. P. Abbott, J. Griffin, R. C. Harris, C. O’ Connor, K. S. Ryder, Circuit World, 2010, 36, 3.

${ }^{26}$ D. Jones, J. Hartley, G. Frisch, M. Purnell, L. Darras, Palaeontologia Electronica, 2012, 15.2.4T.

27 CRC Handbook of Chemistry and Physics, 95th Edition, W. M. Hayney Ed. CRC Press, Boca Raton, USA, 2014.

28 A. P. Abbott, G. Frisch, S. J. Gurman, A. R. Hillman, J. Hartley, F. Holyoak and K. S. Ryder, Chem. Commun., 2011, 47, 10031.

${ }^{29}$ A. P. Abbott, J. C. Barron, G. Frisch, S. Gurman, K. S. Ryder, A. F. Silva, Phys. Chem. Chem. Phys., 2011, 13, 10224.

${ }^{30}$ A. P. Abbott, J. C. Barron, G. Frisch, K. S. Ryder, A. F. Silva, Electrochimica Acta, 2011, 56, 5272.

${ }^{31}$ A. P. Abbott, K. El Ttaib, G. Frisch, K. J. McKenzie and K. S. Ryder, Phys. Chem. Chem. Phys., 2009, 11, 4269.

32 B. Gupta, N. Mudhar and I. Singh, Sep. Purif. Technol., 2007, 57, 294.

33 X. Zhang and G. Yin, Solvent extraction and ion exchange, 2002, 20, 115.

34 R. G. Bautista, Jom-J Min Met Mat S, 2003, 55, 23.

35 J.A. Sturgill, J.T. Swartzbaugh, P.M. Randall, Clean Prod. Proc., 1999, 1, 248.

36 R. Al-Salman, S. Zein El Abedin and F. Endres, Phys. Chem. Chem. Phys., 2008, 10, 4650.

${ }^{37}$ R, Borisenko, S. Zein El Abedin and F. Endres, Electrodeposition from Ionic Liquids F. Endres, D. MacFarlane, A. Abbott Eds. Wiley VCH, Weinheim, 2008, p 147.

38 M. W. Verbrugge, M. K. Carpenter, AIChE J., 1990, 36, 1097.

39 S. P. Wicelinski, R. J. Gale, Proc. Electrochem. Soc., 1986, 86, 144.

40 M. K. Carpenter, M. W. Verbrugge, J. Electrochem. Soc., 1990, 137, 123. 
${ }^{41}$ M. Baghalha, Hydromet. 2012, 113-114, 42.

${ }^{42}$ H. Zhang, C. A. Jeffery, M. I. Jeffrey, Hydromet., 2012, 125-126, 69. 